\title{
How genius can smooth the road to publication
}

\section{If at first your paper doesn't succeed, try, try - and try to find a brilliant supporter.}

Sir - In the entertaining Editorial on journals' faux pas ("Coping with peer rejection”, Nature 425, 645; 2003) the reader is referred to an undoubted success, "perhaps the most celebrated editorial judgements of all" - the publication in Annalen der Physik of five extraordinary papers, all written by Einstein in 1905.

However, when reconciling these events with the current peer-review system, it is worth noting that none of Einstein's papers were sent to reviewers. The decision to publish was made exclusively by either the editor in chief, Max Planck, or the co-editor, Wilhelm Wien — both 'peers' beyond doubt who were later to win the Nobel prize in physics. The importance of these editorial judgements is underlined by the decision of UNESCO to declare 2005 the World Year of Physics to celebrate the centenary of Einstein's 'miraculous' year.

This year we celebrated the 50th anniversary of the publication of the paper by Watson and Crick describing the structure of DNA (Nature 171, 737-738; 1953). Likewise - according to John
Maddox, a former editor of Nature, quoted in the New York Times (25 February 2003) - this manuscript was never sent out to reviewers. The editors accepted the paper upon receipt of a "Publish" covering letter from Nobel laureate Sir Lawrence Bragg.

Thus, to complete the final moral for rejected authors of presumed Nobelwinning work - persist, and get in contact with a noble genius.

Jens Brümmer

Institut für Klinische Chemie,

Universitätsklinikum Hamburg-Eppendorf, 20246 Hamburg, Germany

John Maddox replies - As Jens Brümmer states, the Watson and Crick paper was not peer-reviewed by Nature. I have two comments on this. First, the Crick and Watson paper could not have been refereed: its correctness is self-evident. No referee working in the field (Linus Pauling?) could have kept his mouth shut once he saw the structure. Second, it would have been entirely consistent with my predecessor L. J. F. Brimble's way of working that Bragg's commendation should have counted as a referee's approval. Brimble, who used to "take luncheon" at the Athenaeum in London most days, preferred to carry a bundle of manuscripts with him in the pocket of his greatcoat and pass them round among his chums "taking coffee" in the drawing-room after lunch. I set up a more systematic way of doing the job when I became editor in April 1966.

An interesting question is how Wilkins and Franklin came to have papers in the same issue. J. T. Randall, the head of physics at King's College, was a pal of Brimble's co-editor at the time, A. J. V. Gale, and it is known that Crick sent a copy of his paper to Maurice Wilkins. (He probably sent one to Rosalind Franklin as well.) My guess is that Randall would have called up Gale the minute he heard about Crick's paper, pleading for equal treatment for King's. There's a letter from Wilkins to Crick saying: "Franklin has jumped on the bandwagon - Christ!".

John Maddox, now Emeritus Editor, was Editor of Nature during the periods 1966-1973 and 1980-1995.

\section{Phosphorus: time for us to oust bad spelling}

Sir - I have long suspected that "phosphorus" is the most frequently misspelt word in the environmental sciences, with "phosphorous" - the adjectival spelling — being the primary offender. Although phosphorous is a legitimate adjective meaning phosphorusrich, this is rarely the meaning intended when this spelling is used in the literature. Your News story on the politics of phosphorus pollution in the Everglades, "Judge's sacking rocks Everglades clean-up" (Nature 425, 551; 2003), provides yet another example of this confusion. The word appears eight times in the News story and photo caption, three times ending in "-ous" and five times "-us" the ratio being in favour of propriety, but only marginally.

Many students and colleagues who misspell the word assert that phosphorous is the British spelling. This is clearly not the case. But I wonder if Nature, as a journal with British spellings but a wide audience in the United States, intended a compromise solution to this spelling problem in its News story.

Perhaps the idea is that "yous guys" (an Americanism) and "us guys" can compromise and agree that either spelling is acceptable. But I rather think it is just "us". Nelson Hairston Jr Department of Ecology and Evolutionary Biology, Corson Hall, Cornell University, Ithaca, New York 14853-2701, USA

\section{Drinking your health? It's too early to say}

Sir - There has been much debate in the media about the potential health benefits of moderate wine consumption, and the components of wine that may be responsible. Recently, Konrad Howitz and colleagues reported an increased lifespan for yeast treated with resveratrol through the activation of sirtuins (Nature 425, 191-196; 2003). Because resveratrol is a polyphenol found in wine, these findings have been linked in media reports to studies suggesting that regular wine drinking can increase longevity (for example, see www.nature. com/nsu/030825/030825-1.html; and S. S. Hall, Science 301, 1165; 2003).

However, the claims being made for resveratrol are unjustified. There is no evidence that it would provide these benefits as part of a normal diet - even for wine drinkers.

It is not a simple matter to extrapolate the results of yeast studies to human health, especially when the studies on yeast used much higher concentrations of resveratrol than are available from wine drinking. Levels of resveratrol in wine are generally less than $5 \mathrm{mg}$ per $\mathrm{l}$, and it is heavily metabolized during the absorption process, resulting in extremely low plasma concentrations (D. M. Goldberg et al. Clin. Biochem. 36, 79-87; 2003).

In addition, the link between regular wine consumption and longevity is still not proven. Deaths from coronary heart disease and from all other causes are lower in people drinking two to three glasses of wine a day. This has been interpreted as evidence that regular wine drinking could increase longevity, but it has not yet been confirmed by population studies showing, for example, a large increase in the number of people who live beyond 80 years.

Wine drinking in the pursuit of a longer life should not be encouraged until we have a better understanding of the link between diet and health.

Roger Corder ${ }^{\star}$, Alan Crozier $\dagger$, Paul A. Kroon $\neq$ ${ }^{*}$ William Harvey Research Institute, Charterhouse Square, London EC1M 6BQ, UK $\dagger$ Plant Products and Human Nutrition Group, Institute of Biomedical and Life Sciences, University of Glasgow, Glasgow G12 8QQ, UK ¥Institute of Food Research, Colney Lane, Norwich NR4 7UA, UK 